\title{
ISOLATION AND ANTIMICROBIAL SUSCEPTIBILITY PATTERN OF MICROORGANISMS CAUSING INTRA-ABDOMINAL INFECTIONS AT TERTIARY CARE HOSPITAL OF NORTHERN INDIA
}

\author{
PARMINDER SINGH ${ }^{1}$, RITU GARG $^{2}$, HARIT KUMAR $^{3 *}$, RINKU $^{1}$
}

${ }^{1}$ Department of Microbiology, Molecular Lab, RVRS Government Medical College, Bhilwara, Rajasthan, India. ${ }^{2}$ Department of Microbiology, Maharishi Markandeshwar Institute of Medical Science and Research, Maharishi Markandeshwar University, Mullana, Haryana, India. ${ }^{3}$ Department of Microbiology, Maharishi Markandeshwar Institute of Medical Science and Research, Maharishi Markandeshwar University, Mullana, Haryana, India. Email: kumarharit4@gmail.com

Received: 30 June 2021, Revised and Accepted: 04 September 2021

\section{ABSTRACT}

Objective: The objective of the study is to find out the resistance pattern of pathogenic organisms isolated from intra-abdominal infection (IAI).

Methods: A total of 500 samples were collected from suspected IAIs of patients reporting to the hospital and cultured. Identification of the isolates was done using standard identification protocol. Antimicrobial susceptibility was performed by Kirby-Bauer disc diffusion method and interpretation was done using Central Laboratory Standard Institute guidelines.

Results: Out of 500 samples, 170 were culture positive and 330 showed no growth. Gram-negative organisms (n=127) outnumbered the Gram-positive organisms $(\mathrm{n}=23)$. Among the Gram-negative organisms, Escherichia coli $(\mathrm{n}=67)$ was the most commonly isolated bacilli followed by Klebsiella sp. $(\mathrm{n}=32)$, Pseudomonas sp. $(\mathrm{n}=25)$, Acinetobacter baumannii $(\mathrm{n}=18)$, and Klebsiella oxytoca $(\mathrm{n}=05)$. Among Gram-positive organisms Staphylococcus aureus $(\mathrm{n}=17)$ and Enterococcus spp $(\mathrm{n}=06)$ isolates of were grown in culture. Among Gram-negative bacilli, Imipenem followed by Gentamicin was the most effective drug but in Acinetobacter spp. The second most effective drug was Tigecycline. Among Gram-positive isolates, Linezolid was the most effective drug.

Conclusion: Prompt starting of empirical antimicrobials based on the local susceptibility pattern, followed by modification of treatment in accordance with the antimicrobial susceptibility report can significantly reduce the morbidity and the mortality associated with IAIs.

Keywords: Intra-abdominal infections, Methicillin-resistant Staphylococcus aureus, Empirical antimicrobials, Emerging resistance, Gram-negative organisms, Gram-positive organisms.

(c) 2021 The Authors. Published by Innovare Academic Sciences Pvt Ltd. This is an open access article under the CC BY license (http://creativecommons.org/ licenses/by/4.0/) DOI: http://dx.doi.org/10.22159/ajpcr.2021v14i10.42753. Journal homepage: https://innovareacademics.in/journals/index.php/ajpcr

\section{INTRODUCTION}

Intra-abdominal infections (IAI's) are associated with significant morbidity and mortality and common cause of hospitalized patients [1]. IAIs is a wide term that encompasses a number of infectious processes which include peritonitis, diverticulitis, cholecystitis, cholangitis, pancreatitis, chronic liver failure, and intestinal perforation [2]. According to the Infectious Diseases Society of America, complicated IAIs is defined as an infection that extends beyond the wall of a hollow viscous of source into the abdominal cavity while being related with an abscess or peritonitis [3]. Etiology of the organism responsible for the IAI can be conditional, based on the location of the organ originally infected, since the residential Gastrointestinal flora is typically the cause in the IAIs. For example, infections occurring in the stomach and proximal small intestine mostly involve Gram-positive organisms, whereas those in the distal small intestine involve more Gram-negative aerobic and facultative anaerobic bacilli. Even more distally, infections in the colon consist mainly of obligate anaerobic organisms $[3,4]$. Management of IAIs requires the involvement of multiple modalities such as surgeries as well as treatment with antimicrobials [5]. Hospitalacquired IAIs are associated with higher mortality rates because of compromised patient's immunity due to underlying illness and infections with multidrug-resistant organisms [1]. Antimicrobial management plays a vital role in critically ill patients with IAIs as selection of wrong antimicrobial can cause therapeutically failure which can lead to further mortality rate [6]. Initially, empirical therapy should be started based on the most frequently isolated organism and local pattern of antibiotic susceptibility, which should be modified to specific antimicrobials after receiving the microbiology report of antimicrobial susceptibility of the isolated organism [7]. Growing emergence of resistance to multiple drugs and dearth of local data on antimicrobial resistance pattern of IAIs is the cause of concern for the management of IAIs [8]. By keeping in mind the above facts, the present study was planned to determine the resistance pattern of pathogenic organisms isolated from IAIs.

\section{METHODS}

The present study was conducted for the duration of 2 years, i.e., 2018- 2020 to determine the bacteriological profile and antimicrobial susceptibility pattern of isolates from the samples received from IAIs in the department of Microbiology, MMIMSR, Mullana, Ambala, Haryana, India. Ethical clearance for the study was taken from Institutional Ethical Committee.

\section{Processing of samples}

A total of 500 samples, like - ascetic fluid, bile, pus from intraabdominal cavity, were obtained from patients suffering from IAIs such as peritonitis, cholithiasis, appendicitis, pancreatitis, liver abscess. All the samples were cultured on Blood agar and MacConkey agar and incubated at $37^{\circ} \mathrm{C}$ for $18-24 \mathrm{~h}$ and gram staining was performed on each sample. Identification of isolates was done using standard identification protocol (Mackey and McCartney) and other relevant biochemical tests as appropriate for isolates. Antimicrobial susceptibility testing was done by Kirby-Bauer disc diffusion methods and as per Central Laboratory Standard Institute (CLSI), 2018 guidelines [9-11]. 


\section{Antibiotic susceptibility tests}

Antimicrobial sensitivity pattern of the isolates was performed using Kirby-Bauer disk diffusion method and interpreted according to guidelines of CLSI. Antimicrobial sensitivity testing for Gram-negative isolates was applied using:

a. For Escherichia coli, Klebsiella spp. and Klebsiella oxytoca: Ciprofloxacin $(5 \mu \mathrm{g})$, Piperacillin-Tazobactum $(100 / 10 \mu \mathrm{g})$, Amikacin (30 $\mu \mathrm{g})$, Ceftrixone $(30 \mu \mathrm{g})$, Cefuroxime (30 $\mu \mathrm{g})$, Cefotaxime (30 $\mu \mathrm{g})$, Gentamicin $(10 \mu \mathrm{g})$, Imipenem $(10 \mu \mathrm{g})$, Meropenem $(10 \mu \mathrm{g})$, Cefepime $(30 \mu \mathrm{g})$, Trimethoprim-Sulphomethoxazole $(1.25 / 23.75 \mu \mathrm{g})$

b. For Pseudomonas spp. and Acinetobacter baumanii: Ciprofloxacin $(5 \mu \mathrm{g})$, Levofloxacin $(5 \mu \mathrm{g})$, Gentamicin $(10 \mu \mathrm{g})$, Imipenem $(10 \mu \mathrm{g})$, Meropenem $(10 \mu \mathrm{g})$, Cefepime $(30 \mu \mathrm{g})$, Ceftazidime (30 $\mu \mathrm{g})$, Netilimicin $(30 \mu \mathrm{g})$, Tobramycin $(10 \mu \mathrm{g})$, and Ticarcillin-Clavulanic acid $(75 / 10 \mu \mathrm{g})$.

In addition, Amikacin ( $30 \mu \mathrm{g})$ was also tested against Pseudomonas spp. For A. baumanii Ceftriaxone (30 $\mu \mathrm{g})$, Trimethoprim-Sulphomethoxazole $(1.25 / 23.75 \mu \mathrm{g})$, Piperacillin-Tazobactum $(100 / 10 \mu \mathrm{g})$, Minocycline $(30 \mu \mathrm{g})$, and Tigecycline $(15 \mu \mathrm{g})$ were also additionally tested.

Antibiotics applied for Gram-positive isolates were: Ampicillin (10 $\mu \mathrm{g})$, Erythromycin $(15 \mu \mathrm{g})$, Ciprofloxacin $(5 \mu \mathrm{g})$, Levofloxacin $(5 \mu \mathrm{g})$, Tetracycline $(30 \mu \mathrm{g})$, and Linezolid $(30 \mu \mathrm{g})$.

Additional antibiotics tested against Staphylococcus aureus were Penicillin (10 units), Cefoxitin (30 $\mu \mathrm{g})$, Clindamycin $(2 \mu \mathrm{g})$, Trimethoprim-Sulfamethoxazole (1.25/23.75 $\mu \mathrm{g})$, Minocycline (30 $\mu \mathrm{g})$, and Doxycycline $(30 \mu \mathrm{g})$.

Additional antibiotics tested against Enterococcus spp. was High-level Gentamicin $(120 \mu \mathrm{g})$

Screening for Methicillin-resistance in S. aureus was done using cefoxitin disc as per CLSI guidelines.

\section{RESULTS}

Out of 500 samples collected from clinically suspected cases of IAIs, 405 were indoor patients while 95 were outdoor patients (Table 1). All 500 samples were cultured out of which, 330 showed no growth while growth was obtained in 170 samples. Out of 170 samples, 23 samples showed growth of Gram-positive cocci, in which S. aureus $(\mathrm{n}=17)$ were predominant followed by Enterococcus spp. $(\mathrm{n}=6)$. Among Gramnegative isolates fermentative bacilli $(\mathrm{n}=104)$ were predominant as compared to non-fermentative bacilli $(\mathrm{n}=43)$. Out of all fermentative bacilli $E$. coli was predominant $(\mathrm{n}=67)$ followed by Klebsiella spp. $(\mathrm{n}=32)$ and $K$. oxytoca $(\mathrm{n}=5)$. In non-fermentative bacilli, Pseudomonas spp. $(\mathrm{n}=25)$ were more followed by Acinetobacter baumannii $(\mathrm{n}=18)$ (Table 2)

The most predominant IAIs were Peritonitis and Intestinal perforation in which most isolated organisms were E. coli followed by Klebsiella spp. and Pseudomonas spp. (Table 3).

Table 1: Distribution of patients from IPD and OPD included

\begin{tabular}{lll}
\hline Total no. of samples & IPD & OPD \\
\hline 500 & $405(81 \%)$ & $95(19 \%)$ \\
\hline IPD: Inpatient department, OPD: Outpatient department &
\end{tabular}

Table 2: Total samples showing growth and no growth in clinically suspected cases of IAIs

\begin{tabular}{lllll}
\hline $\begin{array}{l}\text { Total no. } \\
\text { of samples } \\
\text { cultured }\end{array}$ & $\begin{array}{l}\text { No } \\
\text { growth }\end{array}$ & \multicolumn{2}{l}{ With growth (n=170) } & \\
\cline { 3 - 5 } & & GPC* & $\begin{array}{l}\text { GNB } \\
\text { fermenters }\end{array}$ & $\begin{array}{l}\text { GNB non- } \\
\text { fermenters }\end{array}$ \\
\hline 500 & 330 & 23 & 104 & 43 \\
\hline
\end{tabular}

*Gram-positive Cocci, ${ }^{*}$ Gram-negative Bacilli
The Anti-microbial susceptibility testing was also performed in which Imipenem was found to be the most effective drug among all Gram-negative isolates followed by Gentamicin except for Acinetobacter spp. in which the second most effective drug was Tigecycline (Table 4).

All the $S$. aureus $(\mathrm{n}=17)$ isolated were resistant to Cefoxitin, Penicillin and Oxacillin while highly sensitive to Vancomycin, Linezolid (100\%) followed by Teicoplanin (85\%). Among Enterococcus spp., Vancomycin and Linezolid (100\%) were the most sensitive antibiotic followed by Teicoplanin (91\%) (Table 5).

\section{DISCUSSION}

The emergence of resistance to routinely used antibiotics and even to newer antibiotics has made the treatment of IAIs a real challenge as a result accurate laboratory cultures for identification of organisms and their sensitivity testing has to be done with standard protocols. So that the microbiologists and physicians can go to decrease the mortality rate due to IAIs.

In the present study, Inpatient department (IPD) 405 (81\%) patients were predominant over Outpatient department (OPD) 95 (19\%) patients which are suspected IAIs (Table 1). This correlates with the study done by Jangla et al. which showed (76\%) of the patients from IPDs and (24\%) were from OPDs [12].

The rate of positivity from our study was $170 / 500(34 \%)$ in which Gram-negative isolates $(n=147)$ were dominating over Gram-positive isolates $(n=23)$ (Table 2). Among the Gram-negative bacilli, the major isolates were of E. coli $(\mathrm{n}=67)$ followed by Klebsiella spp. $(\mathrm{n}=32)$, K. oxytoca $(\mathrm{n}=5)$ in fermenters and Pseudomonas spp. $(\mathrm{n}=25)$ followed by $A$. baumannii $(\mathrm{n}=18)$ in Non-fermenters. In Gram-positive isolates $S$. aureus $(\mathrm{n}=17)$ were more than Enterococcus spp. $(\mathrm{n}=6)$. These finding correlates with study done by Zhang et al. in which E. coli (47.3\%) is the most common isolate obtained followed by Klebsiella spp. (17.2\%), Pseudomonas spp. (10.1\%), A. baumannii (8.3\%), K. oxytoca (1.8\%) [13]. Garg et al. conducted the same study and revealed that the E. coli $(27.6 \%)$ is the most common isolate obtained in culture-positive samples of IAIs followed by Klebsiella spp. (16.9\%), A. baumannii (12.5\%), Pseudomonas spp. (8.9\%) [5] (Table 3).

In the present study, Peritonitis ( $\mathrm{n}=68$ ) was found to be predominant clinical conditions followed by intestinal perforation $(n=48)$ including Cholelithiasis $(\mathrm{n}=20)$, Appendicitis $(\mathrm{n}=15)$, Pancreatitis $(\mathrm{n}=10)$, and Liver abscess $(n=9)$, respectively (Table 3$)$. According to study done by Sukanya et al. peritonitis perforation (36.1\%) was predominant clinical conditions followed by acute pancreatitis (11.7\%) and necrotic pancreatitis (10\%) [14].

The Anti-microbial susceptibility testing was also performed in which Imipenem was found to be most effective (E. coli- 92.5\%, Klebsiella spp.- 93\%, K. oxytoca- 91\%, Pseudomonas spp.- $94 \%$ and A. baumanii- 88\%) drug among all Gram negative isolates followed by Gentamicin ( $\pm 90 \%$ ) except for A. baumanii in which second most effective drug was Tigecycline (82\%) (Table 4). Similar results were found in study done by Shree et al. showed that the antibiotic resistance rate of Gram-negative isolates to Carbapenems, (Ertapenem - 29-41\%) and (Meropenem - 14-15\%) Imipenem, Tigecycline, and Colistin were most sensitive [15].

In the present study, all the $S$. aureus $(\mathrm{n}=17)$ isolated were resistant to Cefoxitin, Penicillin while highly sensitive to Linezolid (100\%) (Table 5). Overall Enterococcus spp. was also found highly susceptible to Vancomycin and Linezolid (100\%). In accordance of this Shree et al. also stated that $S$. aureus, higher resistance is shown to penicillin (91.7\%), ciprofloxacin (58.4\%), and gentamicin (33.3\%) however, $S$. aureus is $100 \%$ sensitive to Vancomycin and Linezolid [15]. Similarly according to study done by Garg et al. revealed $100 \%$ sensitivity to Vancomycin and Linezolid, 91.66\% to Amikacin and Clindamycin each, Cotrimoxazole 75\%, Erythromycin 58.33\%, and Ciprofloxacin 50\% [5]. 
Table 3: Organisms isolated from various IAIs

\begin{tabular}{|c|c|c|c|c|c|c|c|}
\hline \multirow[t]{2}{*}{ IAI } & \multicolumn{7}{|c|}{ Organisms isolated } \\
\hline & $\begin{array}{l}\text { E. coli } \\
(n=67)\end{array}$ & $\begin{array}{l}\text { Klebsiella } \\
\text { spp. }(\mathrm{n}=32)\end{array}$ & $\begin{array}{l}\text { K. oxytoca } \\
(\mathrm{n}=5)\end{array}$ & $\begin{array}{l}\text { Pseudomonas } \\
\text { spp. }(\mathrm{n}=25)\end{array}$ & $\begin{array}{l}\text { A. baumannii } \\
(\mathrm{n}=18)\end{array}$ & $\begin{array}{l}\text { S. aureus } \\
(\mathrm{n}=17)\end{array}$ & $\begin{array}{l}\text { Enterococcus } \\
\text { spp. }(\mathrm{n}=6)\end{array}$ \\
\hline Peritonitis (n=68) & 20 & 15 & 2 & 11 & 7 & 8 & 3 \\
\hline Intestinal perforation $(n=48)$ & 15 & 4 & 1 & 6 & 4 & 4 & 1 \\
\hline Cholelithiasis $(\mathrm{n}=20)$ & 13 & 5 & 1 & 4 & 2 & 2 & 0 \\
\hline Appendicitis ( $n=15)$ & 6 & 2 & 0 & 2 & 2 & 1 & 1 \\
\hline Pancreatitis $(n=10)$ & 7 & 5 & 0 & 1 & 1 & 1 & 0 \\
\hline Liver abscess ( $n=9)$ & 6 & 1 & 1 & 1 & 2 & 1 & 1 \\
\hline
\end{tabular}

E. coli: Escherichia coli, A. baumannii: Acinetobacter baumannii, K. oxytoca: Klebsiella oxytoca, S. aureus: Staphylococcus aureus, IAIs: Intraabdominal infections

Table 4: Sensitivity Profile of Gram-negative bacilli isolated from IAIs

\begin{tabular}{|c|c|c|c|c|c|}
\hline Antibiotic & $\begin{array}{l}\text { E. coli } \\
(n=67)\end{array}$ & $\begin{array}{l}\text { Klebsiella } \\
\text { spp. }(\mathrm{n}=32)\end{array}$ & $\begin{array}{l}\text { K. oxytoca } \\
(n=5)\end{array}$ & $\begin{array}{l}\text { Pseudomonas spp. } \\
(n=25)\end{array}$ & $\begin{array}{l}\text { A. baumanii } \\
(\mathrm{n}=18)\end{array}$ \\
\hline Ciprofloxacin & $28.50 \%$ & $57.10 \%$ & $58 \%$ & $65 \%$ & $59 \%$ \\
\hline Levofloxacin & $\mathrm{NT}^{+}$ & $\mathrm{NT}^{+}$ & $\mathrm{NT}^{+}$ & $68 \%$ & $62 \%$ \\
\hline Piperacillin-Tazobactum & $62.80 \%$ & $54 \%$ & $59 \%$ & $\mathrm{NT}^{+}$ & $52 \%$ \\
\hline Amikacin & $72.50 \%$ & $60 \%$ & $32 \%$ & $68 \%$ & $\mathrm{NT}+$ \\
\hline Ceftriaxone & $51 \%$ & $21.40 \%$ & $32 \%$ & $\mathrm{NT}^{+}$ & $39 \%$ \\
\hline Cefuroxime & $52 \%$ & $42 \%$ & $48 \%$ & $\mathrm{NT}^{+}$ & $\mathrm{NT}+$ \\
\hline Gentamicin & $85.70 \%$ & $92 \%$ & $90 \%$ & $91 \%$ & $75 \%$ \\
\hline Imipenem & $92.50 \%$ & $93 \%$ & $91 \%$ & $94 \%$ & $88 \%$ \\
\hline Meropenem & $69.25 \%$ & $65 \%$ & $61 \%$ & $82 \%$ & $72 \%$ \\
\hline Cefepime & $61 \%$ & $50 \%$ & $55 \%$ & $69 \%$ & $42 \%$ \\
\hline Trimethoprim-Sulphmethoxazole & $21.40 \%$ & $42.80 \%$ & $45 \%$ & $\mathrm{NT}^{+}$ & $40 \%$ \\
\hline Ceftazidime & $\mathrm{NT}^{+}$ & $\mathrm{NT}^{+}$ & $\mathrm{NT}^{+}$ & $72 \%$ & $55 \%$ \\
\hline Netilimicin & $\mathrm{NT}^{+}$ & $\mathrm{NT}^{+}$ & $\mathrm{NT}^{+}$ & $65 \%$ & $62 \%$ \\
\hline Tobramycin & $\mathrm{NT}^{+}$ & $\mathrm{NT}^{+}$ & $\mathrm{NT}^{+}$ & $78 \%$ & $69 \%$ \\
\hline Ticarcillin-clavulanic acid & $\mathrm{NT}^{+}$ & $\mathrm{NT}^{+}$ & $\mathrm{NT}^{+}$ & $58 \%$ & $62 \%$ \\
\hline Tigecycline & $\mathrm{NT}^{+}$ & $\mathrm{NT}^{+}$ & $\mathrm{NT}^{+}$ & $\mathrm{NT}^{+}$ & $82 \%$ \\
\hline
\end{tabular}

$\mathrm{NT}^{+}=$Not Tested. E. coli: Escherichia coli, K. oxytoca: Klebsiella oxytoca, A. baumanii: Acinetobacter baumanii, IAIs: Intra-abdominal infections

Table 5: Sensitivity Profile of Gram-positive cocci isolated from IAIs

\begin{tabular}{lll}
\hline Antibiotic & $\begin{array}{l}\text { S. aureus } \\
(\mathbf{n = 1 7})\end{array}$ & $\begin{array}{l}\text { Enterococcus } \\
\text { spp. (n=6) }\end{array}$ \\
\hline Ampicillin & 0 & $72 \%$ \\
Penicillin & 0 & $\mathrm{NT}^{+}$ \\
Cefoxitin Screening & 0 & $\mathrm{NT}^{+}$ \\
Erythromycin & $42 \%$ & $42 \%$ \\
Clindamycin & $55 \%$ & $\mathrm{NT}^{+}$ \\
Ciprofloxacin & $35 \%$ & $62 \%$ \\
Levofloxacin & $49 \%$ & $68 \%$ \\
Tetracycline & $45 \%$ & $45 \%$ \\
Trimethoprim-sulfomethoxazole & $68 \%$ & $\mathrm{NT}^{+}$ \\
Minocycline & $78 \%$ & $\mathrm{NT}^{+}$ \\
Doxycycline & $69 \%$ & $\mathrm{NT}^{+}$ \\
Vancomycin & $\mathrm{NT}^{+}$ & $100 \%$ \\
Linezolid & $100 \%$ & $100 \%$ \\
High level gentamicin & $\mathrm{NT}^{+}$ & $84 \%$ \\
\hline
\end{tabular}

S. aureus: Staphylococcus aureus, IAIs: Intra-abdominal infections

This study correlates with another study done by Liu et al. which showed $100 \%$ sensitivity to Vancomycin and Linezolid, while High-level resistant was shown in Penicillin (93.34\%), Erythromycin (84.62\%), and Ciprofloxacin (73.68\%) [16].

\section{CONCLUSION}

The present study emphasizes the need for antimicrobial susceptibility testing of clinically significant isolates from IAIs as a routine practice. Knowing the prevalent pattern of antimicrobial resistance is an important issue especially when Gram-negative isolates continue to exhibit widespread resistance to various currently in use antimicrobial agents. Prompt starting of empirical antimicrobials based on the local susceptibility pattern, followed by modification of treatment in accordance with the antimicrobial susceptibility report which can significantly reduce the morbidity and the mortality associated with IAIs.

\section{AUTHOR CONTRIBUTION}

Concept and design of the study were done by the first, second, and fourth author. Data collection, Data Analysis and manuscript writing were done by first, second, and corresponding author.

\section{CONFLICT OF INTEREST}

Authors declare no conflicts of interests.

\section{AUTHOR FUNDING}

Self.

\section{REFERENCES}

1. Sartelli M, Catena F, Ansaloni L, Leppaniemi A, Taviloglu K, van Goor $\mathrm{H}$, et al. Complicated intra-abdominal infections in Europe: A comprehensive review of the CIAO study. World J Emerg Surg 2012;7:36.

2. De Frances CJ, Cullen KA, Kozak LJ. National hospital discharge survey: 2005 annual summary with detailed diagnosis and procedure data. Vital Health Stat 2007;165:1-209.

3. Marshall J, Innes M. Intensive care unit management of intra-abdominal 
infection. Crit Care Med 2003;31:2228-37.

4. Mazuski JE, Solomkin JS. Intra-abdominal infections. J Surg Clin North Am 2009;89:421-37.

5. Garg R, Singh VA. Bacteriological profile and antimicrobial susceptibility Pattern of Intra-abdominal infections: A study from a tertiary care hospital of North India. J Gastrointest Infect 2017;7:21-5.

6. Dellinger RP, Levy MM, Rhodes A, Annane D, Gerlach H, Opal SM, et al. Surviving sepsis campaign: International guidelines for management of severe sepsis and septic shock, 2012. Crit Care Med 2013;41:580-637.

7. Saad U, Anwar S, Kahara UZ, Siddiqui M, Saeed H. Antimicrobial susceptibility of intra-abdominal infection isolates from a tertiary care hospital in Karachi. J Ayub Med Coll Abbottabad 2016;28:568-71.

8. Chaudhary U, Shamma M, Yadav A. Antimicrobial susceptibility patterns of common and unusual Enterococcus species isolated from clinical specimens. J Infect Dis Antimicrob Agents 2007;24:55-62.

9. Colle JG, Miles RS, Watt B. Tests for identification of bacteria In: Collee JG, editor. Mackie and McCartney Practical Medical Microbiology. 14 $4^{\text {th }}$ ed. Edinburgh: Churchill Livingstone; 1996. p. 151- 79 .

10. Ananthanarayan R, Paniker CK. Urinary tract infections. In: Kapil A, editor. Text Book of Microbiology. $9^{\text {th }}$ ed. Hyderabad, India: University Press; 2013. p. 671.
11. Clinical and Laboratory Standard Institute (CLSI). Performance Standards for Antimicrobial Susceptibility Testing. Twenty Third Informational Supplement. United States: Clinical and Laboratory Standard Institute; 2018. p. 44-61.

12. Jangla SM, Naidu R. Study of bacteriological profile and antibiotic sensitivity pattern in samples received from patients attending tertiary care hospital in Mumbai. J Evol Med Dent Sci 2018;7:284-90.

13. Chen YH, Hsueh PR, Badal RE, Hawser SP, Hoban DJ, Bouchillon SK, et al. Antimicrobial susceptibility profiles of aerobic and facultative Gram-negative bacilli isolated from patients with intra-abdominal infections in the Asia-Pacific region according to currently established susceptibility interpretive criteria. J Infect 2011;62:280-91.

14. Sudhaharan S, Kanne P, Vemu L, Chavali P, Desmukha SR, Nagari B. Bacteriological profile of intra-abdominal infections in a tertiary care hospital. Iran J Microbiol 2018;10:208-14

15. Shree N, Arora BS, Mohil RS, Kasana D, Biswal I. Bacterial profile and patterns of antimicrobial drug resistance in intra-abdominal infections: Current experience in a teaching hospital. Indian J Pathol Microbiol 2013;56:388-92.

16. Liu Q, Ren J, Wu X, Wang G, Wang Z, Wu J, et al. Shifting trends in bacteriology and antimicrobial resistance among gastrointestinal fistula patients in China: An eight-year review in a tertiary-care hospital. BMC Infect Dis 2017;17:637. 